(C)2006 IEEE. Personal use of this material is permitted. However, permission to reprint/republish this material for advertising or promotional purposes or for creating new collective works for resale or redistribution to servers or lists, or to reuse any copyrighted component of this work in other works must be obtained from the IEEE. 


\section{Analysis, Design and Experimentation of a Zero-Voltage Switching Two-Inductor Boost Converter with Integrated Magnetics}

\author{
Quan Li \\ Central Queensland University \\ Rockhampton Mail Center, QLD 4702, Australia \\ Email: q.li@cqu.edu.au
}

\author{
Peter Wolfs \\ Central Queensland University \\ Rockhampton Mail Center, QLD 4702, Australia \\ Email: p.wolfs@cqu.edu.au
}

\begin{abstract}
A Zero-Voltage Switching (ZVS) two-inductor boost converter with an integrated magnetic structure has been previously proposed to achieve the size and cost reduction in the converter design with discrete magnetics. In the integrated magnetic structure, the five copper windings and the four cores required by the two input inductors, the resonant inductor and the transformer in the original ZVS converter are reduced to three copper windings and one three-limbed core. This paper presents a detailed magnetic analysis of the ZVS two-inductor boost converter with the magnetic integration. The equivalent input and transformer magnetising inductances are established in terms of the reluctances of the individual core limbs and the numbers of the individual windings. This allows the converter with the integrated magnetics to be modelled and analysed using an equivalent design with discrete magnetics. The effects of the leakage reluctances are also considered. The magnetic circuit analysis tool can be also used for any other converters with magnetic integration. In the magnetic design process, the peak and the ac flux densities in the three core limbs are solved explicitly so that saturation and core loss calculation can be easily performed. Finally the theoretical waveforms of a $40-W$ $1-\mathrm{MHz}$ ZVS converter are also provided to verify the theoretical analysis.
\end{abstract}

\section{INTRODUCTION}

The two-inductor boost converter has been previously developed by applying the duality principle to the conventional half bridge converter and possesses several attractive features such as high dc voltage gain, low switch voltage stress, full utilization of the transformer windings, ease of transformer volt-second balance and relaxed diode reverse recovery requirements [1]. They have found extensive applications where low dc voltages need to be transformed to higher levels [2]-[5]. A ZVS two-inductor boost converter with additional resonant inductor and capacitors has also been proposed as shown in Fig. 1 [6]. The resonant topology allows the converter to achieve reasonable efficiencies at high switching frequencies and the converter size can be reduced.

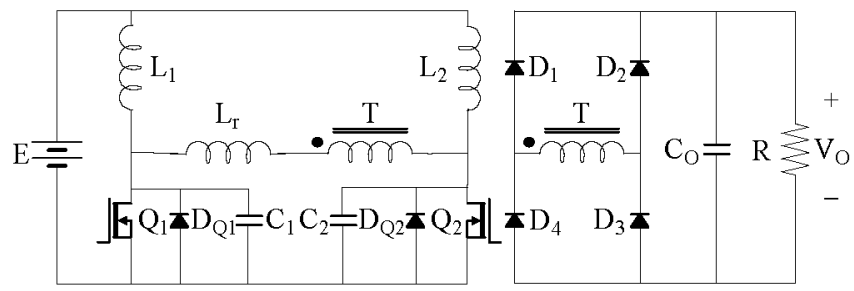

Fig. 1. ZVS two-inductor boost converter
However, an obvious barrier for further size and cost reduction for the converter is the requirement of three separate magnetic components in the hard-switched topology and four separate magnetic components in the softswitched topology. Recently, four possible magnetic integration solutions have been proposed for the twoinductor boost converter so that the converter size and cost can be optimised [7]-[10]. In one particular magnetic integration solution with three windings on a single core, the transformer primary and secondary windings are located on the separate core limbs. Consequently, the coupling between the transformer primary and secondary is extremely loose and large leakage inductance results. Therefore, this solution can only be applied to the soft-switched two-inductor boost converter as shown in Fig. 2, where the two windings on the outer core limbs perform as both the input inductors and the transformer primary and the resonant inductance is purely realized by the leakage inductance [11].

This paper presents the detailed analysis of the ZVS twoinductor boost converter with integrated magnetics. The equivalent input and transformer magnetising inductances are explicitly established through the magnetic circuit analysis. This method can be easily applied to all other converters with magnetic integration. The analysis of the dc and ac fluxes in the individual core limbs is also presented for the magnetic design. The experimental waveforms of a prototype 40-W 1-MHz converter are provided at the end of the paper to validate the theoretical analysis.

\section{Switching State Analysis}

In order to solve the equivalent input and transformer magnetising inductances of the ZVS two-inductor boost converter with integrated magnetics, the switching state analysis of the converter shown in Fig. 1 is provided first. In the analysis, the derivatives of the converter instantaneous input and transformer secondary currents are solved and will be used as the templates in obtaining the explicit formulas of the input and the transformer magnetising inductances of the converter shown in Fig. 2. As consistency is required for the ease of comparison in due course, the converter in Fig. 1 is redrawn in Fig. 3, where the resonant inductor is relocated to the transformer secondary side and a voltage-doubler rectifier is used in the rectification stage. The switching state analysis of the converter shown in Fig. 1 is performed within one switching period and the converter equations in the individual switching states are listed in Table I. 


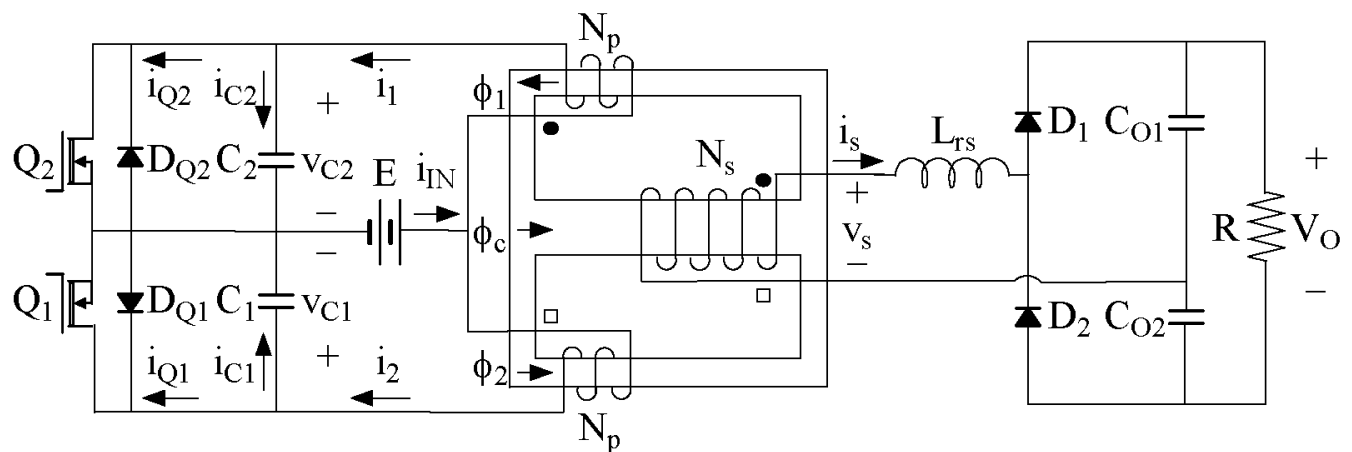

Fig. 2. ZVS two-inductor boost converter with integrated magnetics

TABLE I

SwTiching State Analysis of the ZVS Two-Indcutor Boost Converter with Discrete Magnetics

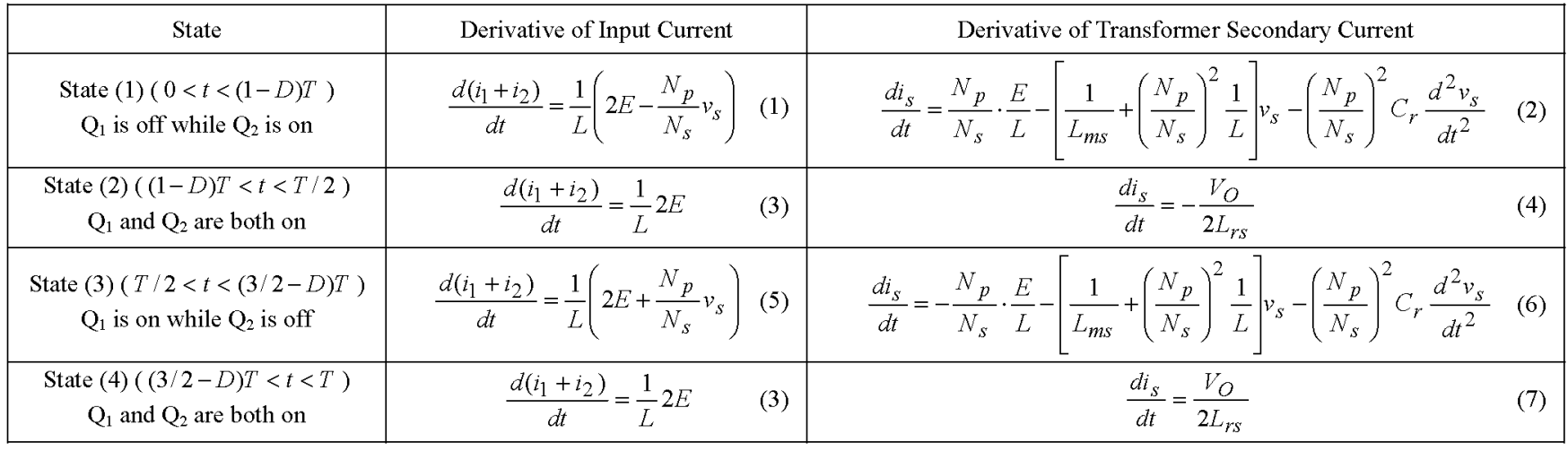



Fig. 3. ZVS converter with the resonant inductance referred to the transformer secondary side

In Table I, $\mathrm{N}_{\mathrm{p}}$ and $\mathrm{N}_{\mathrm{s}}$ are respectively the transformer primary and secondary numbers of turns, $\mathrm{D}$ is the switching duty ratio and $T$ is the switching period, $L_{m s}$ is the transformer magnetizing inductance referred to the secondary, $L=L_{1}=L_{2}$ is the input inductance and $C_{r}=C_{1}=C_{2}$ is the resonant capacitance.

\section{Equivalent INPUT AND MAgnetizing INDUCTANCES}

The equivalent input and magnetizing inductances of the ZVS two-inductor boost converter can be established through the analysis of the magnetic circuit and switching states of the converter shown in Fig. 2.

The magnetic circuit of the core and winding arrangement in Fig. 2 is shown in Fig. 4, where $\mathfrak{R}_{0}$ and $\mathfrak{R}_{\mathrm{c}}$ are respectively the reluctances of the outer and centre core limbs and $\phi_{1}, \phi_{2}$ and $\phi_{\mathrm{c}}$ are respectively the instantaneous fluxes in the individual core limbs. The magnetic circuit is valid for all four switching states defined in Table I and the fluxes in the individual core limbs can be calculated as:

$$
\begin{gathered}
\phi_{1}=\frac{N_{p} i_{1}}{\mathfrak{R}_{o}+2 \mathfrak{R}_{c}}\left(1+\frac{\mathfrak{R}_{c}}{\mathfrak{R}_{o}}\right)-\frac{N_{s} i_{s}}{\mathfrak{R}_{o}+2 \mathfrak{R}_{c}}+\frac{N_{p} i_{2}}{\mathfrak{R}_{o}+2 \mathfrak{R}_{c}} \cdot \frac{\mathfrak{R}_{c}}{\mathfrak{R}_{o}}(8) \\
\phi_{2}=\frac{N_{p} i_{1}}{\mathfrak{R}_{o}+2 \mathfrak{R}_{c}} \cdot \frac{\mathfrak{R}_{c}}{\mathfrak{R}_{o}}+\frac{N_{s} i_{s}}{\mathfrak{R}_{o}+2 \mathfrak{R}_{c}}+\frac{N_{p} i_{2}}{\mathfrak{R}_{o}+2 \mathfrak{R}_{c}}\left(1+\frac{\mathfrak{R}_{c}}{\mathfrak{R}_{o}}\right)(9) \\
\phi_{c}=\frac{N_{p} i_{1}}{\mathfrak{R}_{o}+2 \mathfrak{R}_{c}}-\frac{2 N_{s} i_{s}}{\mathfrak{R}_{o}+2 \mathfrak{R}_{c}}-\frac{N_{p} i_{2}}{\mathfrak{R}_{o}+2 \mathfrak{R}_{c}}
\end{gathered}
$$

Applying Faraday's Law to the three windings in the converter shown in Fig. 2 yields:

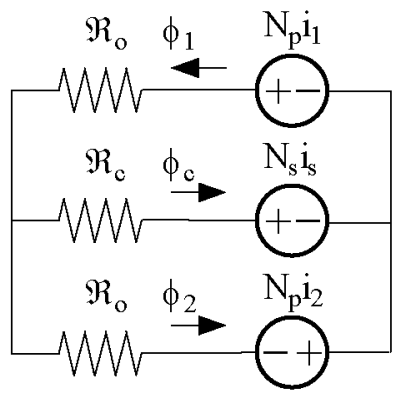

Fig. 4. Magnetic circuit 


$$
\begin{gathered}
N_{p} \frac{d \phi_{1}}{d t}=E-v_{C 2} \\
N_{p} \frac{d \phi_{2}}{d t}=E-v_{C 1} \\
N_{s} \frac{d \phi_{C}}{d t}=v_{s}
\end{gathered}
$$

The winding currents and core limb fluxes in the converter shown in Fig. 2 are respectively:

$$
\begin{gathered}
i_{1}=i_{Q 2}+C_{r} \frac{d v_{C 2}}{d t} \\
i_{2}=i_{Q 1}+C_{r} \frac{d v_{C 1}}{d t} \\
\phi_{1}=\phi_{2}+\phi_{c}
\end{gathered}
$$

The converter in Fig. 2 can be analysed under three different operating conditions:

- State $(1)\left(\mathrm{Q}_{1}\right.$ is off while $\mathrm{Q}_{2}$ is on $)$

In this state, $v_{C 2}=0$ and $i_{Q 1}=0$. Manipulations of (8) to (16) yield:

$$
\begin{gathered}
\frac{d\left(i_{1}+i_{2}\right)}{d t}=\frac{\Re_{o}}{N_{p}^{2}}\left(2 E-\frac{N_{p}}{N_{s}} v_{s}\right) \\
\frac{d i_{s}}{d t}=\frac{\Re_{o}}{N_{p} N_{s}} E-\frac{\Re_{o}+\Re_{c}}{N_{s}^{2}} v_{s}-\left(\frac{N_{p}}{N_{s}}\right)^{2} C_{r} \frac{d^{2} v_{s}}{d t^{2}}
\end{gathered}
$$

By defining $\mathrm{L}_{\mathrm{a}}$ and $\mathrm{L}_{\mathrm{b}}$ to be

$$
\begin{gathered}
L_{a}=\frac{N_{p}^{2}}{\Re_{o}} \\
L_{b}=\frac{2 N_{s}^{2}}{\left(\Re_{o}+2 \Re_{c}\right)}
\end{gathered}
$$

(17) and (18) can be simplified as:

$$
\begin{gathered}
\frac{d\left(i_{1}+i_{2}\right)}{d t}=\frac{1}{L_{a}}\left(2 E-\frac{N_{p}}{N_{s}} v_{s}\right) \\
\frac{d i_{s}}{d t}=\frac{N_{p}}{N_{s}} \cdot \frac{E}{L_{a}}-\left[\frac{1}{L_{b}}+\left(\frac{N_{p}}{N_{s}}\right)^{2} \frac{1}{2 L_{a}}\right] v_{s}-\left(\frac{N_{p}}{N_{s}}\right)^{2} C_{r} \frac{d^{2} v_{s}}{d t^{2}}
\end{gathered}
$$

- State (3) $\left(\mathrm{Q}_{1}\right.$ is on while $\mathrm{Q}_{2}$ is off)

In this state, $v_{C 1}=0$ and $i_{Q 2}=0$. Manipulations of (8) to (16) yield:

$$
\begin{gathered}
\frac{d\left(i_{1}+i_{2}\right)}{d t}=\frac{\Re_{o}}{N_{p}^{2}}\left(2 E+\frac{N_{p}}{N_{s}} v_{s}\right) \\
\frac{d i_{s}}{d t}=-\frac{\Re_{o}}{N_{p} N_{s}} E-\frac{\Re_{o}+\Re_{c}}{N_{s}^{2}} v_{s}-\left(\frac{N_{p}}{N_{s}}\right)^{2} C_{r} \frac{d^{2} v_{s}}{d t^{2}}
\end{gathered}
$$

Substitution of (19) and (20) into (23) and (24) yields:

$$
\begin{gathered}
\frac{d\left(i_{1}+i_{2}\right)}{d t}=\frac{1}{L_{a}}\left(2 E+\frac{N_{p}}{N_{s}} v_{s}\right) \\
\frac{d i_{s}}{d t}=-\frac{N_{p}}{N_{s}} \cdot \frac{E}{L_{a}}-\left[\frac{1}{L_{b}}+\left(\frac{N_{p}}{N_{s}}\right)^{2} \frac{1}{2 L_{a}}\right] v_{s}-\left(\frac{N_{p}}{N_{s}}\right)^{2} C_{r} \frac{d^{2} v_{s}}{d t^{2}}
\end{gathered}
$$

- States (2) and (4) $\left(\mathrm{Q}_{1}\right.$ and $\mathrm{Q}_{2}$ are both on)

In this state, $v_{C 1}=v_{C 2}=0$ and manipulations of (8) to (16) yield:

$$
\begin{aligned}
\frac{d\left(i_{1}+i_{2}\right)}{d t} & =\frac{\Re_{o}}{N_{p}^{2}} 2 E \\
v_{s} & =0
\end{aligned}
$$

Substitution of (19) into (27) yields:

$$
\frac{d\left(i_{1}+i_{2}\right)}{d t}=\frac{1}{L_{a}} 2 E
$$

According to (28), the derivative of the transformer secondary current can be obtained as (4) or (7).

Comparisons of (21), (22), (25), (26) and (29) respectively with their counterparts in the converter with discrete magnetics in Table I yield:

$$
\begin{gathered}
L=\frac{N_{p}^{2}}{\mathfrak{R}_{o}} \\
L_{m s}=\frac{N_{s}^{2}}{\mathfrak{R}_{c}}
\end{gathered}
$$

Equation (30) implies that the input inductance of the converter with the integrated magnetic structure is proportional to the square of the number of turns of the outer core limb winding and inversely proportional to the outer core limb reluctance only. Equation (31) implies that the transformer secondary magnetizing inductance is proportional to the square of the number of turns of the centre core limb winding and inversely proportional to the centre core limb reluctance only. 


\section{Magnetic DESIGN}

The implementation of the ZVS two-inductor boost converter with integrated magnetics demands a three-limb core structure. Equation (30) confirms that other than the number of turns of the windings on the outer core limb, the input inductance is also determined by the reluctance of the outer core limb. Often the outer core limb may be gapped as would be the core in a discrete inductor to prevent the limb from saturation. The centre core limb reluctance determines the magnetising inductance therefore a gap would not normally be applied in the centre core limb.

The other two design parameters for the magnetic core are the peak flux density, which is critical in the saturation protection and the ac flux density, which is useful in the core loss estimation. The dc and ac fluxes will be analysed separately.

Assuming that $I_{1}, I_{2}, I_{8}$ and $I_{\mathbb{N}}$ are respectively the dc components of $i_{1}, i_{2}, i_{s}$ and $i_{\mathrm{NN}}$ over the entire switching period, the following equations can be established as the operation of the ZVS two-inductor boost converter is half cycle symmetrical:

$$
\begin{gathered}
I_{1}=I_{2}=\frac{I_{I N}}{2} \\
I_{S}=0
\end{gathered}
$$

Assuming that $I_{1, j}, I_{2, j}$ and $I_{s, j}$ are respectively the dc components of $i_{1}, i_{2}$ and $i_{s}$ in State $(j)$, where $j=1,2,3,4$, the following equation can be established:

$$
I_{w}=\sum_{j=1}^{4} D_{j} I_{w, j}, w=1,2, s, j=1,2,3,4
$$

where $D_{j}$ is defined as:

$$
D_{j}= \begin{cases}1-D, & j=1,3 \\ D-\frac{1}{2}, & j=2,4\end{cases}
$$

According to Fig. 4, the instantaneous fluxes in the three core limbs are restricted by the following equations:

$$
\begin{gathered}
\mathfrak{R}_{o} \phi_{1}+\mathfrak{R}_{o} \phi_{2}=N_{p}\left(i_{1}+i_{2}\right)=N_{p} i_{I N} \\
\mathfrak{R}_{o} \phi_{1}+\mathfrak{R}_{c} \phi_{c}=N_{p} i_{1}-N_{s} i_{s}
\end{gathered}
$$

Equations (16), (36) and (37) can be respectively rewritten to (38) to (40) with the dc components of the variables in each state, where $\Phi_{1}, \Phi_{2}$ and $\Phi_{\mathrm{c}}$ are the dc components of $\phi_{1}$, $\phi_{2}$ and $\phi_{\mathrm{c}}$ in each switching state and as well over the entire switching period:

$$
\begin{gathered}
\Phi_{1}=\Phi_{2}+\Phi_{c} \\
\mathfrak{R}_{o} \Phi_{1}+\mathfrak{R}_{o} \Phi_{2}=N_{p} I_{I N} \\
\mathfrak{R}_{o} \Phi_{1}+\mathfrak{R}_{c} \Phi_{c}=N_{p} I_{1, j}-N_{s} I_{s, j}, j=1,2,3,4
\end{gathered}
$$

Manipulations of (32) to (40) yield

$$
\begin{gathered}
\Phi_{1}=\Phi_{2}=\frac{N_{p} I_{I N}}{2 \Re_{o}} \\
\Phi_{c}=0
\end{gathered}
$$

\begin{tabular}{|c|c|c|}
\hline Resonant State & Circuit Diagram & Instantaneous Bottom Outer Core Limb Flux Equation \\
\hline $\begin{array}{l}\text { State (a) }\left(0 \leq t \leq t_{1}\right) \\
\mathrm{Q}_{1} \text { turns off when } i_{L r}=-\Delta_{1} I_{0}\end{array}$ & 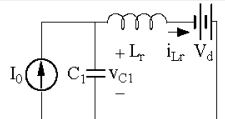 & $\phi_{2}(t)=\frac{\left(E+V_{d}\right) \omega_{0} t+\left(1+\Delta_{1}\right) I_{0} Z_{0}\left(\cos \omega_{0} t-1\right)-V_{d} \sin \omega_{0} t}{\omega_{0} N_{p}}+\phi_{2}(0)$ \\
\hline $\begin{array}{c}\text { State (b) }\left(t_{1} \leq t \leq t_{2}\right) \\
\mathrm{C}_{1} \text { linearly charges }\end{array}$ & 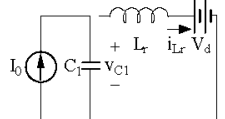 & $\phi_{2}(t)=\frac{\left[E-v_{C l}\left(t_{1}\right)\right]\left(t-t_{1}\right)-I_{0}\left(t-t_{1}\right)^{2} /\left(2 C_{1}\right)}{N_{p}}+\phi_{2}\left(t_{1}\right)$ \\
\hline $\begin{array}{l}\text { State }(\mathrm{c})\left(t_{2} \leq t \leq t_{3}\right) \\
\mathrm{C}_{1} \text { resonates with } \mathrm{L}_{\mathrm{r}}\end{array}$ & 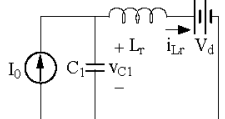 & $\phi_{2}(t)=\frac{\left(E-V_{d}\right) \omega_{0}\left(t-t_{2}\right)+I_{0} Z_{0}\left[\cos \omega_{0}\left(t-t_{2}\right)-1\right]-\left[v_{C 1}\left(t_{2}\right)-V_{d}\right] \sin \omega_{0}\left(t-t_{2}\right)}{\omega_{0} N_{p}}+\phi_{2}\left(t_{2}\right)$ \\
\hline $\begin{array}{c}\text { State }(\mathrm{d})\left(t_{3} \leq t \leq t_{4}\right) \\
\mathrm{Q}_{1} \text { turns on when } v_{C 1}=0\end{array}$ & 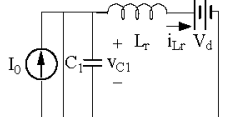 & $\phi_{2}(t)=\frac{E\left(t-t_{3}\right)}{N_{p}}+\phi_{2}\left(t_{3}\right)$ \\
\hline
\end{tabular}

The ac fluxes in the individual core limbs need to be obtained numerically from the corresponding instantaneous fluxes, which can be analysed through the resonant state analysis of the converter shown in Fig. 1 within half switching period after the MOSFET $\mathrm{Q}_{1}$ turns off since the converter with integrated magnetics can be modelled by the one with discrete magnetics as discussed in Section III. The results are given in Table II.

TABLE II

Instantaneous Bottom Outer Core Limb Flux in Each Resonant State 
In the circuit diagrams in Table II, the resonant inductance, the current source and the voltage source are respectively $L_{r}=\frac{N_{p}^{2}}{N_{s}^{2}} L_{r s}, I_{0}=\frac{I_{I N}}{2}$ and $V_{d}=\frac{N_{p}}{2 N_{s}} V_{O}$. In (43) to (46), $\omega_{0}=\frac{1}{\sqrt{L_{r} C_{r}}}$ and $Z_{0}=\sqrt{\frac{L_{r}}{C_{r}}}$ are respectively the characteristic angular resonance frequency and impedance of the resonant tank. The derivation of the initial flux $\phi_{2}(0)$ will be given in due course. It is also worth mentioning that in the resonant state analysis, State (b) has a possibility to be bypassed if the initial resonant inductor current in State (a) is large enough to result in a capacitor voltage $v_{C l}$ higher than $V_{d}$ at the end of State (a).

In both States (a) and (b), it can be observed that $\phi_{2}$ increases but with a reducing rate as long as $v_{C 1}<E$ and decreases with an increasing rate when $v_{C 1}>E$. In state (c), $\phi_{2}$ keeps decreasing with an increasing rate until $\mathrm{v}_{\mathrm{Cl}}$ reaches its peak, continues to decrease as long as $v_{C 1}>E$ and again increases at an increasing rate when $v_{C 1}<E$. In state (d), $\phi_{2}$ increases linearly as $v_{C 1}=0$. Therefore, the flux $\phi_{2}$ reaches its maximum $\phi_{2 \text {,max }}$ when the capacitor voltage $\mathrm{v}_{\mathrm{Cl}}$ first reaches $E$ in either State (a) or (b) and reaches its minimum $\phi_{2 \text {,min }}$ when the capacitor voltage $\mathrm{v}_{\mathrm{Cl}}$ drops back to $\mathrm{E}$ in State (c). As the ZVS two-inductor boost converter is half cycle symmetrical, the ac fluxes in the two outer core limbs $\left|\Delta \phi_{1}\right|$ and $\left|\Delta \phi_{2}\right|$ are equal and they can be calculated by numerically integrating (12) between the times when the flux $\phi_{2}$ reaches $\phi_{2, \max }$ and $\phi_{2 \text {,min. }}$. Once the ac flux is sovled, the peak flux $\phi_{2, \max }$ can be obtained as:

$$
\phi_{2, \max }=\Phi_{2}+\frac{\left|\Delta \phi_{2}\right|}{2}
$$

The initial flux $\phi_{2}(0)$ can then be derived by subtracting the flux increase between the instant when MOSFET $\mathrm{Q}_{1}$ turns off and the instant when $\mathrm{v}_{\mathrm{Cl}}$ first reaches $\mathrm{E}$ from the peak flux $\phi_{2, \max }$.

The flux $\phi_{1}$ in the top outer core limb can be analysed in the same way. Under symmetrical operation, the flux waveforms of the two outer core limbs are the same except that they are phase shifted with $180^{\circ}$.

Because the transformer primary and secondary windings are loosely coupled in Fig. 2, the resonant inductance can be purely realized from the transformer leakage inductance. In this case, the leakage flux in the transformer is significant and the flux paths are not constrained within the core structure. Considering the leakage flux, the magnetic circuit shown in Fig. 4 can be redrawn in Fig. 5 , where $\mathfrak{R}_{\mathrm{a}}$ is the reluctance of the transformer leakage flux path in the air and $\phi_{\mathrm{le}}$ is the transformer leakage flux. The centre core limb and leakage fluxes are respectively:

$$
\begin{gathered}
\phi_{c}=\phi_{1}-\phi_{2}-\phi_{l e} \\
\phi_{l e}=\frac{L_{r s} i_{s}}{N_{s}}
\end{gathered}
$$

Finally, a 3F3 ETD29 core with a 0.5-mm air gap in each of the two outer core limbs and a cross section area of 71 $\mathrm{mm}^{2}$ is used in the converter design. Other key parameters in the magnetic design are:

- The number of turns for the primary and secondary windings are respectively $N_{p}=10$ and $N_{s}=13$.

- The leakage inductance reflected to the transformer secondary is $L_{l e s}=12.39 \mu \mathrm{H}$.

The converter frequency is selected as $1 \mathrm{MHz}$ which corresponds to a device switching frequency of $500 \mathrm{kHz}$. When $E=20 \mathrm{~V}$ and $I_{I N}=2 \mathrm{~A}$, the dc and ac fluxes and flux densities in different core limbs are given in Table III.

\section{THEORETICAL AND EXPERIMENTAL WAVEFORMS}

From top to bottom, Fig. 6 respectively shows the theoretical waveforms of the bottom outer core limb ac flux $\phi_{2, \mathrm{ac}}$, the centre core limb ac flux $\phi_{\mathrm{c}, \mathrm{ac}}$, the MOSFET drain source voltage $\mathrm{v}_{\mathrm{Cl}}$ and the transformer secondary current $\mathbf{i}_{\mathrm{s}}$. The two ac flux waveforms are plot using (43) to (46), (48) and (49) and the voltage and current waveforms are plot using equations in [6].

A prototype converter with $40-\mathrm{W}$ and $20-\mathrm{V}$ input has been built to verify the theory and the experimental waveforms are shown in Fig. 7. The top two waveforms in Fig. 7 are respectively the ac flux waveforms of $\phi_{2}$ and $\phi_{\mathrm{c}}$ as recovered by integrating the voltage of a single search turn wound on the transformer core limb. The bottom two waveforms are respectively the resonant capacitor voltage $v_{C 1}$ and transformer secondary current $i_{s}$. It can be seen that the experimental waveforms agree reasonably well with the theoretical waveforms.

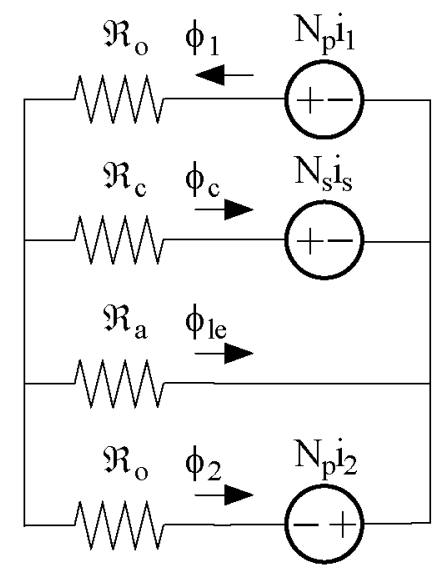

Fig. 5. Magnetic circuit with leakage path 
TABLE III

DC and AC Fluxes and Flux Densities In the Individual Core Limbs

\begin{tabular}{|c|c|c|c|c|c|}
\hline Core Limb & DC Flux $(\mu W b)$ & AC Flux $(\mu W b-p p)$ & AC Flux Density $(m T-p p)$ & Peak Flux $(\mu W b)$ & Peak Flux Density $(\mathrm{mT})$ \\
\hline Outer & 0.89 & 2.54 & 71.5 & 2.16 & 60.8 \\
\hline Centre & 0 & 2.30 & 32.4 & 1.15 & 16.2 \\
\hline
\end{tabular}

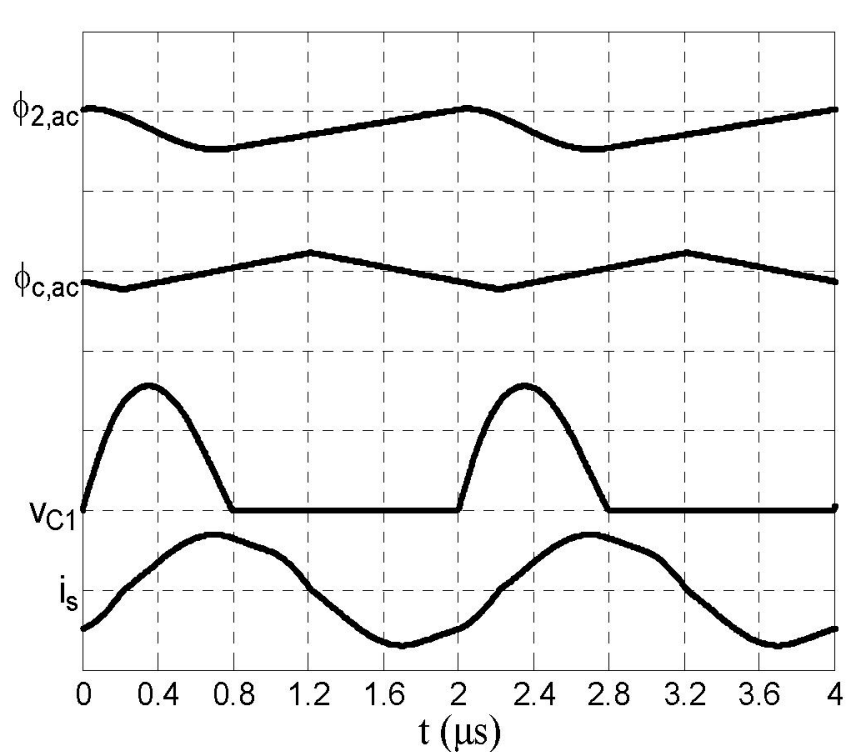

Fig. 6. Theoretical waveforms $\phi_{2, \text { ac }}(5 \mu \mathrm{Wb} / \mathrm{div}), \phi_{\mathrm{c}, \mathrm{ac}}(5 \mu \mathrm{Wb} / \mathrm{div})$, $\mathrm{v}_{\mathrm{Cl}}(50 \mathrm{~V} / \mathrm{div})$ and $\mathrm{i}_{\mathrm{s}}(3 \mathrm{~A} /$ div $)$

A conversion efficiency of $93 \%$ has been recorded by using the mathematics functions of a Tektronix TDS5034 oscilloscope equipped with the input and output voltage and current probes.

\section{COnClusions}

In this paper, a detailed analysis of the ZVS two-inductor boost converter is presented. In order to model the proposed converter with the conventional converter employing discrete magnetics, the equivalent converter input inductance and the transformer magnetizing inductance are explicitly established through the analysis of the magnetic circuit. Both peak and ac flux densities in the individual core limbs are solved and this allows further analysis of the magnetic core saturation and loss to be carried out. The magnetic circuit analysis tool can also be a useful foundation in the converter and magnetic design where magnetic integration technique is utilized. Finally, both theoretical and experimental waveforms are demonstrated for a $40-\mathrm{W} 1-\mathrm{MHz}$ prototype converter and good matches are found.

\section{REFERENCES}

[1] P. J. Wolfs, "A current-sourced dc-de converter derived via the duality principle from the half-bridge converter," IEEE Trans. Ind. Electron., Vol. 40, No. 1, pp. 139-144, Feb. 1993.

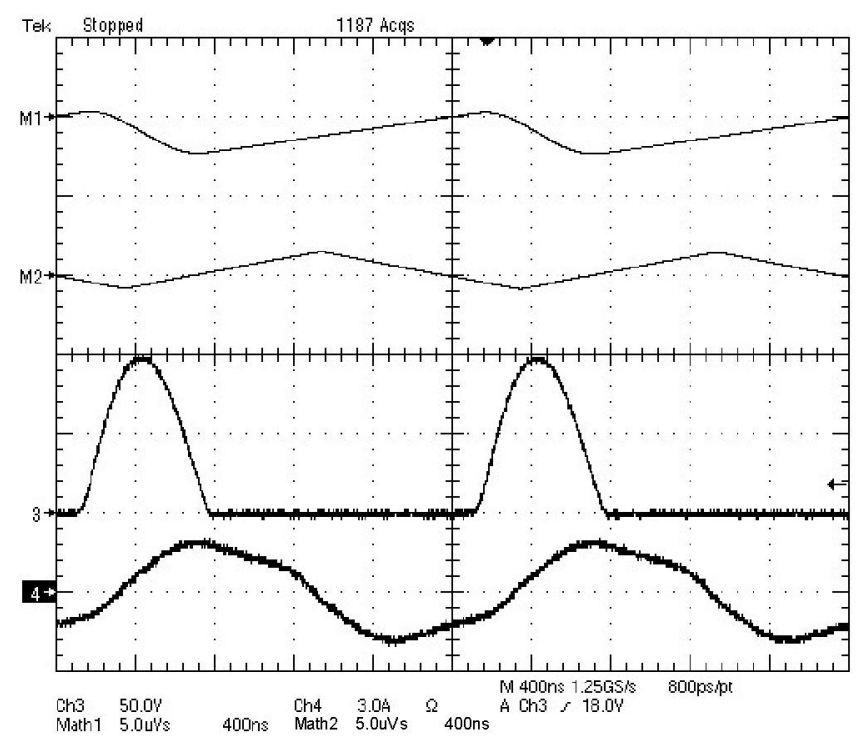

Fig. 7. Experimental waveforms Channel M1 (5 $\mu \mathrm{Wb} /$ div $)$, Channel M2 $(5 \mu \mathrm{Wb} /$ div $)$, Channel 3 (50 V/div) and Channel 4 (3 A/div)

[2] J. Kang, C. Roh, G. Moon and M. Youn, "Phase-shifted parallelinput/series-output dual converter for high-power step-up applications," IEEE Trans. Ind. Electron., Vol. 49, No. 3, pp. 649652, Jun. 2002.

[3] Y. Jang and M. M. Jovanovic, "New two-inductor boost converter with auxiliary transformer," in Proc. IEEE APEC, 2002, pp. 654-660; also IEEE Trans. Power Electron., Vol. 19, No. 1, pp. 169-175, Jan. 2004.

[4] C. Roh, S. Han, S. Hong, S. Sakong and M. Youn, "Dual-coupled inductor-fed DC/DC converter for battery drive applications," IEEE Trans. Ind. Electron., Vol. 51, No. 3, pp. 577-584, Jun. 2004.

[5] L. Yan and B. Lehman, "An integrated magnetic isolated twoinductor boost converter: analysis, design and experimentation," IEEE Trans. Power Electron., Vol. 20, No. 2, pp. 332-342, Mar. 2005.

[6] P. Wolfs and Q. Li, "An analysis of a resonant half bridge dual converter operating in continuous and discontinuous modes," Proc. IEEE PESC, 2002, pp.1313-1318.

[7] L. Yan and B. Lehman, "Isolated two-inductor boost converter with one magnetic core," in Proc. IEEE APEC, 2003, pp. 879-885.

[8] X. Gao and R. Ayyannar, "A novel buck-cascaded two-inductor boost converter with integrated magnetics," in Proc. IEEE INTELEC, 2004, pp. 190-197.

[9] Q. Li and P. Wolfs, "A current fed two-inductor boost converter with lossless snubbing for photovoltaic module integrated converter applications," in Proc. IEEE PESC, 2005, pp. 2111-2117.

[10] Q. Li and P. Wolfs, "A comparison of three magnetics integration solutions for the two-inductor boost converter," in Proc. Australasian Universities Power Engineering Conference, 2005, pp. 629-634.

[11] Q. Li and P. Wolfs, "A leakage-inductance-based ZVS two-inductor boost converter with integrated magnetics," IEEE Power Electron. Lett., Vol. 3, No. 2, pp. 67-71, Jun. 2005. 